\title{
Age at Onset of Menarche and Puberty of Girls in Aydin Region and the Factors Affecting Them
}

\author{
Ebru Ataş Aslan ${ }^{1} \oplus$, Tolga Ünüvar²® \\ ${ }^{1}$ Department of Pediatrics, Aydın Adnan Menderes University \\ Faculty of Medicine, Aydın \\ 2 Department of Pediatric Endocrinology, Aydın Adnan Menderes \\ University Faculty of Medicine, Aydın
}

Cite as: Ataş Aslan E, Ünüvar T. Age at onset of menarche and puberty of girls in Aydin region and the factors affecting them. Trends in Pediatrics 2021;2(1):35-42.

Received: 17 November 2020

Accepted: 30 November 2020

Publication date: 30 March 2021

Keywords: Puberty, menarche, girls

Tolga Ünüvar

Department of Pediatric Endocrinology, Aydın Adnan Menderes University Faculty of Medicine, Aydın, Turkey

ORCID: 0000-0002-5517-5030

tunuvar@gmail.com

\section{E. Ataş Aslan 0000-0002-1266-6251}

\section{ABSTRACT}

Objective: In this study, we aimed to determine the range of mean age at onset of menarche (AOM) and puberty (AOP) of girls living in Aydin province and to determine the factors affecting the onset age of menarche.

Method: A total of 1891 girls aged between 8 and 16 years attending primary, secondary and high schools in Aydin province were planned to be included in the study. A questionnaire that was prepared in line with the literature was delivered to the parents in a closed envelope. The subjects who accepted to participate in the study were examined by an experienced physician by measuring height and weight and pubertal status was defined according to Tanner scale. BMI values were calculated.

Results: In total, 1520 female students were accepted to the study with the permission of their families. The mean AOM of participants was $12.11 \pm 1.32$ years. The mean AOM was $13.12 \pm 1.46$ years for their mothers, and $12.73 \pm 1.25$ years for their sisters. June was the month that menarche occurred most frequently. We observed that the children living in rural areas had an earlier age of menarche. The mean age at onset of puberty was $9.71 \pm 1.46$ years.

Conclusion: Our study is important in terms of being the first study conducted in Aydin province that determined the mean AOM and AOP of girls aged between 8 and 16. In our study, we showed that the age of menarche shifted to an early age, while the age of puberty did not shift. The age at onset of menarche and puberty were similar to the results obtained in other studies conducted in neighboring regions. We believe that larger scale studies may contribute to assess the actual mean age at menarche of girls living in Turkey.

\section{INTRODUCTION}

The first menstruation, or menarche, is an important step of development and indicator of chronological age that shows biological maturity of a girl. ${ }^{1,2}$ Previous studies have shown that the first menstrual experience is remembered negatively rather than being positive or neutral, which proves the importance of the first menstruation. ${ }^{3}$ Menarche is one of the phases of sexual maturation in girls, and it is a physiological event that starts at about 8-9 years of age with changes in neuroendocrine system activity, followed by skeletal maturation, breast development, pubic hair growth, and that occurs within 1.3-1.5 years after rapid height spurt. ${ }^{4}$ Studies have shown that many factors such as genetic factors, socio-economic status, nutrition and high- intensity physical activity can affect the age of menarche. ${ }^{5}$

Menarche follows changes called secondary sex characteristics. Normally, towards the end of adolescence, anovulatory and irregular cycles become menstrual, ovulatory and regular. As a result, complaints about the interval and length of the cycles are also reduced., 5,6 There is increasing evidence that the age at onset of menarche (AOM) has declined in recent years. ${ }^{6,7}$ There is not enough information about what determines the age at menarche, and the underlying genetic mechanism is still not clear. The process of growth and development has accelerated and shifted to an earlier age. This is defined as the 'secular trend'. Malnutrition, chronic diseases, inadequate medical care, individual health, 
genetic characteristics, race, environmental factors, and socio-economic and cultural status of the family may be effective on this shift. ${ }^{7}$

Menarche, as the beginning of the first menstrual period, is a very important turning point in a woman's life. This period is an important indicator of maturity in the evaluation of pubertal development. ${ }^{8,9}$ The $\mathrm{AOM}$ is an indicator of the biological and social conditions of the society. It is an important event that occurs as a result of the sum of biological, environmental and social factors. ${ }^{10}$ The AOM is significantly affected by genetic factors. In addition, it has been reported that it is highly related to the factors such as urbanization, socio-economic status, the number of children in families, nutrition, seasons, and physical activity. ${ }^{11}$ Some researchers have reported that the AOM has declined in developed countries compared to previous years. Studies on the development of puberty in Turkish children are limited. In 1978, Neyzi et al. have reported the mean age at onset of puberty (AOP) in girls with higher socio-economic status living in Istanbul as $9.8 \pm 1.3$ years, and the age of menarche as $12.4 \pm 0.1$ years. In girls with lower socio-economic status, the age at menarche was 0.8-0.9 years later. ${ }^{12}$ However, in a study by Ersoy et al., which has examined 1017 girls, no significant difference has been found between girls with higher and lower socio-economic status in terms of AOM (12.73 \pm 1.07 and $12.87 \pm 1.08$ years). ${ }^{13}$ In a study conducted in 2005, 3311 Turkish schoolage children have been examined and it has been reported that breast development in girls started at 10.16 years, growth of pubic hair at 10.57 years, and menarche at 12.4 years. ${ }^{14}$

As the number of studies examining the age at onset of puberty and menarche in Turkish children and the factors affecting them are limited, it is not known exactly how many Turkish children have been affected by the shift of AOM and AOP, which is the secular trend. In this study, we aimed to determine the range of the mean age at onset of puberty and menarche in girls living in Aydin province and to determine the factors affecting the onset age of menarche.

\section{MATERIALS and METHODS}

Adnan Menderes University Ethics Committee approved the study. We first planned to include 1891 girls aged between 8 and 16 years who were attending primary, secondary and high schools in Aydin province, Turkey. The study was planned as a cross-sectional study, and it was conducted by using the multi-stage sampling method. Aydin province was divided into five regions (east, west, north, south and city center) by considering the socioeconomic status and geographical settlement. One district from each region was selected by simple random sampling. One rural and one urban school (twenty-five schools in total) from the specified district were selected using simple random sampling. Students from the selected schools to be included in the study were stratified according to their grades. The students from each grade were determined from the student lists by using systematic sampling. The total number of students studying at the selected schools was 6028 . The G-power program, a software that is used by the World Health Organization (WHO) to calculate the sample size for population-based researches, was used and the targeted sample size was calculated as 1891. After obtaining the necessary permissions for the study from the Office of the Governor and the Aydin Provincial Directorate of National Education, consent forms were obtained from the families of all children who participated in the study.

A 40-item questionnaire form, which was prepared in line with the literature, was delivered to the parents of the students in a closed envelope. The questionnaire form was consisted of questions such as socio-demographic information about the student and the family, the educational status of the parents, status of social security and monthly income, the AOM of the student, mother and sister, presence of bad habits such as alcohol or cigarette, exercise status, use of mass media, and factors related to puberty. Children with chronic diseases and those on chronic medication were excluded from the study.

An experienced physician who was knowledgeable about anthropometric methods measured the height and weights of the children using the same devices. Body mass index (BMI) $\left(\mathrm{kg} / \mathrm{m}^{2}\right)$ was calculated for each and every child. The BMI and percentile curves for Turkish children were taken as reference. Moreover, the pubertal development of all cases was 
visually determined according to Tanner classification by a female doctor alone, without completely undressing the student. All examinations were performed in a closed and separate room, which was deemed appropriate by the school administration. Girls with Tanner stage 1 breast development were considered prepubertal, and those with Tanner stage 2 breast development and above were considered pubertal.

\section{Statistical analysis}

Statistical analysis was performed using the Windows based SPSS 16.0 program. Kolmogorov-Smirnov test was used to determine whether the quantitative variables were normally distributed. The groups were compared using Mann Whitney U or Kruskal Wallis tests in terms of quantitative variables. Paired comparison tests were performed to determine the groups that showed difference after Kruskal Wallis analysis. Descriptive statistics were given as standard mean \pm standard deviation for all quantitative variables in order to fit the representation commonly used in the literature. For the analysis of categorical variables, Chi-square test was used, and descriptive statistics were given as frequency and percentage. Spearman correlation analysis was used to analyze the relationship between quantitative variables. Values of $p<0.05$ were considered statistically significant.

Adnan Menderes University Scientific Research Projects Unit supported this project with project number: TPF-15007.

\section{RESULTS}

A total of 1520 female students between the ages of 8 and 16, attending primary and high schools, were included in the study with their parents' permission. The mean age of 1520 children was $12.73 \pm 2.65$ years. 133 children had stage 1 thelarche, the others were stage 2 or further. The mean AOP was $9.71 \pm 1.46$ years, while the mean age at onset of pubic hair development was $10.71 \pm 2.16$ years (Table 1 ). The $\mathrm{BMI}$ of the children in the stage 2 thelarche group, which we consider as the age at onset of puberty, was $17.40 \pm 2.76 \mathrm{~kg} / \mathrm{m}^{2}$, and the BMl of the prepubertal group was $15.85 \pm 2.27 \mathrm{~kg} / \mathrm{m}^{2}(p=0.008)$.

The AOP in children consuming fast-food was $9.66 \pm 1.53$ years, and in those who did not consume fast-food was $10 \pm 0.93$ years. The difference between them was statistically significant $(p=0.032)$.

The comparison of physical exercise status showed that girls who did not exercise regularly entered puberty at a statistically earlier age than those who exercised regularly $(p<0.001)$ (Table 2$)$.

Among all participants, 874 children stated that they had menarche, and the mean AOM was $12.11 \pm 1.32$ years. The mean menarcheal age of mothers of children who had menarche was $13.12 \pm 1.46$ years. The mean AOM of the children was significantly lower than the mean AOM of their mothers $(p<0.05)$. The mean AOM of the older sisters of 318 girls who experienced menarche was $12.73 \pm 1.25$ years. The mean AOM of the children was significantly lower than the mean AOM of their sisters $(p<0.05)$. June was the month that menarche occurred most frequently. Looking at the seasonality, summer was the season with highest rate of experiencing menarche (39.06\%). The mean AOM of children living in rural areas was significantly earlier $(11.75 \pm 1.21)$ than the children living in urban areas (12.15 \pm 1.32$)(p=0.006)$.

Table 1. The mean age values of the children according to stages of thelarche and pubarche

\begin{tabular}{lcc} 
& Age of thelarche $($ mean $\pm s d)$ & Age of pubarche $($ mean $\pm s d)$ \\
Stage 1 & $9.13 \pm 1.32$ & $9.43 \pm 1.34$ \\
Stage 2 & $9.71 \pm 1.46$ & $10.71 \pm 2.16$ \\
Stage 3 & $11.60 \pm 2.40$ & $12.81 \pm 2.34$ \\
Stage 4 & $13.70 \pm 1.94$ & $14.48 \pm 1.44$ \\
Stage 5 & $14.70 \pm 1.08$ & $14.63 \pm 1.20$ \\
\hline Total & & 1520
\end{tabular}


Table 2. Age of onset of puberty in children who exercising regularly and in those who do not exercise regularly

\begin{tabular}{|l|r|r|}
\hline Status of regular exercise & Age of onset of puberty (mean \pm sd) & $\mathbf{n}$ \\
\hline Doing exercise & $9.96 \pm 1.40$ & 50 \\
\hline Not doing exercise & $9.61 \pm 1.48$ & 127 \\
\hline Total & & 177 \\
\hline
\end{tabular}

When we compared the mean AOM and mother's education level, we found that children of illiterate mothers experienced menarche at an earlier age than children whose mothers were primary school graduates $(p=0.046)$ and secondary school graduates $(p=0.042)(p=0.003)$. The comparison between mean $\mathrm{AOM}$ and the social security status of the mother showed that the children whose mother had a social security coverage and whose socioeconomic status was better experienced their menarche at an earlier time in ( $p=0.002)$. When AOM and maternal marital status were compared, we showed that children of married mothers had their menstruation earlier than children of divorced mothers $(p=0.005)$ and children of separated parents $(p=0.003)$.

The comparison between AOM and delivery method demonstrated that the AOM of children born by cesarean section was earlier than those born by normal spontaneous vaginal delivery $(p<0.001)$. When $\mathrm{AOM}$ and time of birth were compared in all groups, we found that children born postmature and premature experienced menarche at an earlier age $(p=0.004$ and $p=0.017$, respectively) than children who were born on normal time.

\section{DISCUSSION}

Since many years, it is well known that the growthdevelopment process and the age of puberty are significantly affected by genetic and ethnic characteristics, as well as environmental factors such as geographical location, nutritional status and life style. Since the middle of the $19^{\text {th }}$ century, the living conditions of people living in industrialized countries have improved and towards the end of the century, due to advancements in knowledge on nutrition and protection against infectious diseases, the children have been better nourished, protected from infections and ultimately improved. As this was a prominent development seen in the $20^{\text {th }}$ century, it was called the secular trend, and it has affected the pubertal development as well as growth. ${ }^{15}$

Studies have shown that the mean AOM has declined in developed countries, and this decline has also been observed in developing countries in recent years, as well. ${ }^{16}$ Environmental changes, better nutrition, and consequently physical development likely have led to this change. The decline in age of menarche in the last century is accepted as a positive indicator of the health status of the population. ${ }^{17}$

The most comprehensive study conducted in the United States of America (USA) is a cross-sectional study by Herman-Giddens et al. ${ }^{18}$, involving 17,077 girls aged between 3-12 years. In this study, it has been shown that the AOP of African-American girls was earlier than the age of white girls, and according to previous USA data, puberty had shifted to younger ages. ${ }^{19}$

In studies conducted in Turkey, in 1975, Neyzi et al. have reported the age at onset of puberty as 9.8 years $^{20}$ and in 2011, Atay et al. have reported it as 9.65 years. ${ }^{21}$ In our study, the AOP was $9.71 \pm 1.46$ years. Although our result is similar to the Atay's study, it suggests the age of puberty has shifted to a younger age in the past 40 years. When we compared our results with the studies conducted in Europe, we found that the mean AOP was significantly lower. ${ }^{22,23}$

A recent study conducted in Europe in 2006, the age at onset of pubarche has been reported as $11.29 \pm 2.01$ years. ${ }^{23}$ In studies conducted in Turkey, in 1975, Neyzi et al. have reported the mean age at onset of pubic hair growth as 10.4 years $^{20}$, while Atay et al. have stated this age as 10.09 years. ${ }^{21}$ In our study, the mean age at onset of pubarche was 10.71 \pm 2.16 years, and this result is similar to previous studies conducted in our country. We thought that the 
reason for the lack of a significant change in the age at onset of pubarche over the years may be that other pathways and endocrine systems such as the adrenal gland might be effective in onset of pubarche other than the hypothalamic-pituitary-gonadal (HPG) axis.

A longitudinal study conducted in Sweden has shown that children with high BMI entered puberty at an earlier age. ${ }^{24}$ In our study, BMI of girls with stage 2 thelarche was significantly higher than the prepubertal ones, and that the age at onset of puberty of the children consuming fast food was earlier than children who did not consume any fastfood. We already know that the increase in mean fat tissue in childhood has an effect on the onset of puberty, but consumption of fast food increases calorie density, resulting in greater energy intake. ${ }^{25}$ Increased adipose tissue increases the aromatization of androgens to estrogens, and as BMI increases, the HPG axis is positively affected, thus shifting the age of puberty to an earlier time. In their study, Merzanich et al. have suggested that regular physical activities and active training increase energy expenditure, lower BMI and delay menarche. ${ }^{26}$ In our study, we demonstrated that girls who do not exercise regularly enter puberty at a statistically earlier age than those who exercise regularly. Increased physical activity has an effect on menarche, changes in energy balance and body composition..$^{25,26}$ The increased physical activity decreases the body fat ratio and blood levels, and as a result, the menarche is delayed. This result suggests that the age at menarche can be delayed in case of regular physical activity.

In 1960s, Marshall and Tanner have reported the mean age of menarche as $13.5 \pm 0.1$ years in girls living in England. ${ }^{22}$ Wyshak et al. have shown that the AOM shifts 2-3 months earlier every 10 years in Europe. ${ }^{16}$ In the study conducted by Neyzi et al. in 1975 in our country, the age of menarche has been found as $12.4 \pm 0.1$ years. In their study, Neyzi et al. have also investigated the socio-economic status and they have found that as the socioeconomic status increased, the frequency of menarche in these age groups also increased. ${ }^{20}$ In 2011, Atay et al. have reported the age of menarche as 12.74 years and it has been stated that the result of this study was almost the same with Neyzi's study, a study that was conducted 40 years ago.
In their study, Ersoy et al. have determined the mean age of menarche as $12.82 \pm 1.07$ years. ${ }^{13}$ In our study, mean age of menarche was $12.11 \pm 1.32$ years. The results of our study are similar to previously conducted Turkish studies. It is clear that there may be regional differences in our country due to geographical, cultural and socio-economic diversifications. In addition, many immigrants are welcomed to our country from neighboring countries because of an ongoing civil war. Therefore, in order to find the true mean age of menarche in Turkey, similar studies should be conducted in other regions of Turkey.

The similarities between mother-daughter and sisters show the effect of hereditary factors on age of menarche. The similarity between sisters is generally more than the similarity between mother-daughter, and this situation reveals that the common interaction resulting from the shared family environment affects individuals from the same generation more than individuals belonging to different generations. ${ }^{27}$

In a study conducted by Al Alwan et al. in Saudi Arabia. ${ }^{28}$, the mean AOM was $13.08 \pm 1.10$ years, and the mother's menarcheal age was $13.67 \pm 1.40$ years. It has been shown that girls experience menarche at an earlier age than their mothers. In our study, the mean AOM was significantly lower than the mean AOM of older sisters and mothers, which shows the effect of genetic factors on AOM. Considering the fact that AOM of children are significantly lower than the mean AOM of mothers and older sisters, we can suggest that the mean AOM of Turkish girls have shifted to a younger age. A similar result obtained in our study depends on the facts that the living conditions of children have gradually improved, they have got better health care services and their socioeconomic status have converged. Due to the similar living conditions and genetic characteristics of the sisters, the mean AOM has come closer to each other and shifted to an earlier time than the menarcheal age of their mothers.

Many studies conducted in Europe have shown that menarche is associated with study tempo at school and holiday periods. The frequency of menarche increases during or with the onset of holidays. ${ }^{29}$ The stress experienced due to school activities may have a negative effect on puberty and on the contrary, 
puberty is positively affected during the holiday periods when students relax. Matchcock et al. have shown that the most frequent month for menarche occurrence was June (14.5\%), followed by January $(12 \%) .{ }^{30}$ In our study, June (19\%) and February (11\%) were the months that menarche occurred most frequently. Throughout the year, summer was the season with most frequent menarches (39.06\%). Considering that June is the month when summer holiday starts and February is the month when winter break starts, we can conclude that menarche frequency increases in holiday seasons and this may be a result of relaxation of children after intense school pace and exam stress.

Today, while the secular trend continues in developing countries, it has come to a halt in many developed countries. ${ }^{31}$ There are differences between the rural and urban residents of the same country as well as between countries. In a study conducted in 2005 and covering different geographical regions of China where 92.757 girls between the ages of 9-18 were included, it has been shown that the AOM was 12.76 years in rural areas and 12.60 years in the city. The AOM has been found to be earlier for girls living in the city than in rural areas. Our study has demonstrated that the mean AOM of children living in rural areas was earlier than children living in the city. We can attribute this to the fact that the living conditions of rural and urban areas are getting close to each other, children continue their school education in larger schools, and grow up in the same environment.

In a study investigating the age of menarche in Poland and examining both retrospective and prospective data, age of delayed menarche was found to be associated with low educated parents (especially for mother) and poor performance at school. ${ }^{32}$ In our study, the age of menarche was found to be earlier in the group whose mother did not attend any school. Considering the living conditions of Turkey, mother having the basic education and increased awareness should positively affect the children, leading to delayed menarche in children of these mothers.

In a study conducted about 20 years ago in high schools in Istanbul, the mean age at menarche was
$12.58 \pm 1.04$ years in the high socio-economic status group, $13.03 \pm 0.89$ years in the middle socioeconomic status group, and $13.33 \pm 1.10$ years in the low socio-economic status group. ${ }^{33}$ In our study, we demonstrated that the AOM was earlier in children with a higher family socioeconomic status. The AOM may have shifted to an earlier time because of the family's social security, economic freedom and better living standards. In addition, the increase in prevalence of obesity and BMI may also have contributed to this shift.

Toromanovic et al. have demonstrated that the age of menarche of girls with single or divorced mothers were earlier than girls with married mothers. ${ }^{34}$ In a study by Kurdzielewicz, it has been shown that children with broken families had delayed menarchy. ${ }^{32}$ It has been suggested that the high pressure in these families affect the HPG axis. In our study, the AOM was found later in children with separated parents. In a healthy and safe environment, where the children grow with their parents, hitting puberty and timely functioning of the HPG axis help menarche begin within the physiological period. We think that the stress experienced by children with separated parents puts pressure on the HPG axis, which may cause a delay of menarche.

Ruder et al. have compared the age at menarche and birth characteristics, and have found that a birth weight below $500 \mathrm{~g}$ was associated with delayed menarche (approximately 2.7 months). ${ }^{35}$ In our study, children born at term experienced menarche at a later age than children born pre and post-term. We can suggest that the AOM of children who have completed intrauterine life in its normal process and physiology is later than the AOM of others. This situation can be interpreted as stimulation of the HPG axis during the growth of premature babies. In the future, more information can be obtained on this subject if studies are carried out to reveal the age at onset of menarche of premature babies.

Ethics Committee Approval: Adnan Menderes University Ethics Committee approved the study.

Conflict of Interest: The authors declared no potential conflicts of interest with respect to the research, authorship, and/or publication of this article.

Funding: Adnan Menderes University Scientific Re- 
search Projects Unit supported this project with project number: TPF-15007.

Informed Consent: Medical students, nurse trainees, and parents of the patients provided informed consent to publish the report.

\section{REFERENCES}

1. Malina RM, Bouchard C. Growth, Maturation, And Physical Activity. Champaign, IL: Human Kinetics. 1991;2:2-30.

2. Malina RM. Menarche in athletes: a synthesis and hypothesis. Annals of Human Biology. 1983;10:1-24. https://doi.org/10.1080/03014468300006141

3. Meyer JM, Eaves, LJ, Heath AC, Martin NG. Estimating genetic influences on the age at menarche: a survival analysis approach. American Journal of Medical Genetics. 1991;39:148-54

https://doi.org/10.1002/ajmg.1320390207

4. Henneberg M, Louw GJ. Average menarcheal age of higher socioeconomic status urban cape coloured girls assessed by means of status-quo and recall methods, American Journal of Physical Anthropology. 1995;96:1-5. https://doi.org/10.1002/ajpa.1330960102

5. Simodon KB, Simon Y, Simodon F. Nutritional status and age at menarche of Senegalese adolescents. Annals of Human Biology. 1997;24:521-32. https://doi.org/10.1080/03014469700005282

6. Terasawa E, Fernandez DL. Neurobiological mechanisms of the onset of puberty in primates. Endocr Rev. 2001;22:111-51.

https://doi.org/10.1210/edrv.22.1.0418

7. Partsch CJ, Heger S, Sippell WG. Management and outcome of central precocious puberty. Clin Endocrinol. 2002;56:129-48. https://doi.org/10.1046/j.0300-0664.2001.01490.x

8. Ojeda SR, Lomniczi A, Mastronardi C, Heger S, Roth C, Parent AS, Matagne V, Mungenast AE. Minireview: the neuroendocrine regulation of puberty: is the time ripe for a systems biology approach?. Endocrinology. 2006;147:1166-74.

https://doi.org/10.1210/en.2005-1136

9. Garibaldi L. Disorders of pubertal development. In: Kliegman R (eds). Nelson Textbook of Pediatrics, $21^{\text {th }}$ ed. Philadelphia, Elsevier, 2020; 2309-11.

10. Mitamura R, Yano K, Suzuki N, Ito Y, Makita Y, Okuno A. Diurnal rhythms of luteinizing hormone, folliclestimulating hormone, testosterone, and estradiol secretion before the onset of female puberty in short children. J Clin Endocrinol Metab. 2000;85:1074-80. https://doi.org/10.1210/jc.85.3.1074

11. Brito VN, Batista MC, Borges MF, Latronico AC, Kohek $\mathrm{MB}$, Thirone AC, Jorge BH, Arnhold IJ, Mendonca BB. Diagnostic value of fluorometric assays in the evaluation of precocious puberty. J Clin Endocrinol Metab. 1999;84:3539-44.

https://doi.org/10.1210/jcem.84.10.6024

12. Saka HN, Neyzi O. Puberte başlangıç yaşı değişiyor mu? Türk Pediatri Arşivi. 2005;40:7-14.

13. Ersoy B, Balkan C, Gunay T, et al. Effects of different socioeconomic conditions on menarche in Turkish female students. Early Hum Dev. 2004;76:115-25. https://doi.org/10.1016/j.earlhumdev.2003.11.001

14. Semiz S, Kurt F, Kurt DT, Zencir M, Sevinç O. Pubertal development of Turkish children. J Pediatr Endocrinol Metab. 2008;21:951-61. https://doi.org/10.1515/JPEM.2008.21.10.951

15. Sánchez-Andrés A. Genetic and environmental factors affecting menarcheal age in Spanish women. Anthropol Anz. 1997;55(1):69-78. https://doi.org/10.1127/anthranz/55/1997/69

16. Wyshak G, Frish RE. Evidence for a secular trend in age of menarche. N Engl J Med. 1982;306:1003-5. https://doi.org/10.1056/NEJM198204293061707

17. Nebesio TD, Eugster EA. Current concepts in normal and abnormal puberty. Curr Probl Pediatr Adolesc Health Care. 2007;37:50-72. https://doi.org/10.1016/j.cppeds.2006.10.005

18. Herman-Giddens ME, Slora EJ, Wasserman RC, et al. Secondary sexual characteristics and menses in young girls seen in office practice: a study from the Pediatric Research in Office Settings network. Pediatrics. 1997;99(4):505-12. https://doi.org/10.1542/peds.99.4.505

19. Lee PA. Normal ages of pubertal events among American malesand females. J Adolesc Health Care. 1980;1:26-9. https://doi.org/10.1016/S0197-0070(80)80005-2

20. Neyzi O, Alp H, Orhan A. Sexuel maturation in Turkish girls. Ann Hum Biol. 1975;2:49-59. https://doi.org/10.1080/03014467500000561

21. Atay Z, Turan S, Guran T, Furman A, Bereket A. Puberty and influencing factors in schoolgirls living in Istanbul: end of the secular trend? Pediatrcs. 2011 Jul;128: 40-5. https://doi.org/10.1542/peds.2010-2267

22. Marshall WA, Tanner JM. Variations in pattern of pubertal changes in girls. Arch Dis Child 1969;44:291303. https://doi.org/10.1136/adc.44.235.291

23. Juul A, Teilmann G, Scheike $T$, et al. Pubertal development in Danish children: comparison of recent European and US data. Int J Androl. 2006;29:247-55. https://doi.org/10.1111/j.1365-2605.2005.00556.x

24. He Q, Karlberg J. Bmi in childhood and its association with height gain, timing of puberty, and final height. Pediatr Res. 2001;49(2):244-51. https://doi.org/10.1203/00006450-200102000-00019

25. Bowman SA, Gortmaker SL, Ebbeling CB, et al. Effects of fast-food consumtion on energy intake and diet quality among chidren in a national household survey. Pediatrics. 2004;113:112-8. https://doi.org/10.1542/peds.113.1.112

26. Merzenich $\mathrm{H}$, Boeing $\mathrm{H}$, Wahrendorf J. Dietary fat and sports activity as determinants for age at menarche. American Journal of Epidemiology. 1993;138:110-4. https://doi.org/10.1093/oxfordjournals.aje.a116850

27. Chavarro J, Villamor E, Narvaez J, et al. Socio-demografic predictors of age at menarche in a group of Colombian University women. Annals of Human Biology. 2004;31:245-57. https://doi.org/10.1080/03014460310001652239

28. Al Alwan IA, Ibrahim AA, Badri MA, Al Dubayee MS, Bin-Abbas BS. Decline in menarcheal age among Saudi 
girls. Saudi Med J. 2015;36(11):1324-8.

https://doi.org/10.15537/smj.2015.11.13604

29. Gueresi P. Monthly distribution of menarche in three provinces of North Italy. Annals Hum Biol. 1997;24:15768.

https://doi.org/10.1080/03014469700004892

30. Matchock RL, Susman EJ, Brown FM. Seasonal rhythms of menarche in the United States: Correlates to menarcheal age, birth age, and birth month. Womens Health Issues. 2004;14:184-92.

https://doi.org/10.1016/j.whi.2004.07.007

31. Parent AS, Teilmann G, Juul A, Skakkebaek NE, Toppari J, Bourguignon JP. The timing of normal puberty and the age limits of sexual precocity: variations around the world, secular trends, and changes after migration. Endocr Rev. 2003;24:668-93. https://doi.org/10.1210/er.2002-0019

32. Kurdzielewicz M. Analysis of selected environmental and biophysical parameters during menarche. Ann Acad Med Stetin. 2001;47:125-43.

33. Tümerdem $Y$, Ayhan B. Genç kızlarda menstrual sikluslarda, davranış ve duygu değişimlerine eğitimin etkinliği (Epidemiyolojik Araştırma). Turkish Journal of Medical Sciences. 1989;13:166-71.

34. Toromanovic A, Tahirovic H. Effect of family disintegration on age at menarche. Acta Med Acad. 2015;44:124-34.

35. Ruder EH, Dorgan JF, Kranz S, Kris-Etherton PM, Hartman TJ. Examining breast cancer growth and lifestyle risk factors: early life, childhood, and adolescence. Clin Breast Cancer. 2008;4:334-42. https://doi.org/10.3816/CBC.2008.n.038 